\title{
Consumption of regular-fat vs reduced-fat cheese reveals gender-specific changes in LDL particle size - a randomized controlled trial
}

Farinaz Raziani ${ }^{1}$, Parvaneh Ebrahimi ${ }^{2}$, Søren Balling Engelsen², Arne Astrup ${ }^{1}$, Anne Raben ${ }^{1}$ and Tine Tholstrup ${ }^{1}$

\begin{abstract}
Background: Regular-fat cheese does not seem to increase low density lipoprotein cholesterol (LDL-C) concentrations compared to reduced-fat cheese. However, plasma LDL-C concentrations do not reflect levels and size of LDL particles, which might be a better predictor of cardiovascular risk.

Methods: The aim was to compare the effects of regular-fat cheese vs reduced-fat cheese and carbohydrate-rich foods on LDL particle size distribution in adults with $\geq 2$ metabolic syndrome (MetS) risk factors. The study was part of a 12 weeks' randomized controlled trial in which subjects had been randomly allocated to 1 of 3 intervention groups; regular-fat cheese (REG), reduced-fat cheese (RED) or a no-cheese/carbohydrate (CHO) group. Subjects in the REG and RED groups consumed $80 \mathrm{~g}$ cheese/d per $10 \mathrm{MJ}$, whereas subjects in the $\mathrm{CHO}$ consumed bread and jam corresponding to $90 \mathrm{~g} / \mathrm{d}$ and $25 \mathrm{~g} / \mathrm{d}$ per $10 \mathrm{MJ}$, respectively. Fasting blood samples at wk. 0 (baseline) and wk. 12 were analyzed for LDL particle size distribution and cholesterol content using nuclear magnetic resonance (NMR) spectroscopy.

Results: A total of 85 subjects [mean \pm SD age: $54.0 \pm 12.8$ y; BMl: $28.7 \pm 3.6 \mathrm{~kg} / \mathrm{m}^{2}$ ] completed the study. Overall, regular-fat cheese did not impact lipoprotein particle number and size differently than reduced-fat cheese. In men $(n=$ 23), the REG diet decreased total LDL particle number ( $L D L-P,-223.2 \pm 91.1 \mathrm{nmol} / \mathrm{l}, P=0.01$ ) compared with the RED diet. The reduction was primarily in the medium-sized $L D L$ fraction $(-128.5 \pm 51.8 \mathrm{nmol} / \mathrm{l}, P=0.01)$. In women $(n=62)$, the REG diet increased the concentration of cholesterol in the small high density lipoprotein (HDL) particles compared with the $\mathrm{CHO}$ diet $(2.9 \pm 1.0 \mathrm{mg} / \mathrm{dl}, P=0.006)$.
\end{abstract}

Conclusion: Overall, regular-fat cheese did not alter LDL particle size distribution compared to reduced-fat cheese after a 12 wk. intervention in subjects with $\geq 2$ MetS risk factors. However, our results suggest that lipoprotein response to cheese intake is gender-specific. This warrants further investigation.

Trial registration: This trial was registered at Clinicaltrials.gov as NCT0261471. Registered 30 November 2015 Retrospectively registered.

Keywords: Saturated fat, NMR, Dairy, Metabolic syndrome

\footnotetext{
* Correspondence: parvaneh.ebrahimi@med.lu.se

${ }^{2}$ Department of Food Science, Faculty of Science, University of Copenhagen,

Rolighedsvej 26, 1958 Frederiksberg C, Denmark

Full list of author information is available at the end of the article
}

(c) The Author(s). 2018 Open Access This article is distributed under the terms of the Creative Commons Attribution 4.0 International License (http://creativecommons.org/licenses/by/4.0/), which permits unrestricted use, distribution, and reproduction in any medium, provided you give appropriate credit to the original author(s) and the source, provide a link to the Creative Commons license, and indicate if changes were made. The Creative Commons Public Domain Dedication waiver (http://creativecommons.org/publicdomain/zero/1.0/) applies to the data made available in this article, unless otherwise stated. 


\section{Background}

Epidemiological studies have revealed that reducing plasma cholesterol levels results in clinically relevant reductions in risk factors for cardiovascular disease (CVD) [1]. Although increased plasma low density lipoprotein cholesterol (LDL-C) concentrations is considered one of the main CVD risk factors, a number of individuals who develop atherosclerosis and CVD have LDL-C concentrations in the normal range [2]. The main reason for this observation is that LDL particles are heterogeneous in respect to size, density, and physiochemical properties [3]. In the case of LDL, the concentration of LDL-C does not reflect the levels of LDL particle size. Studies show that a higher presence of small, dense LDL (sdLDL) particles is associated with a higher risk of CVD [4, 5], independent of plasma LDL-C concentrations $[6,7]$.

The main focus of dietary recommendations for CVD prevention and management has been a reduction of dietary fat, in particular saturated fatty acids [8]. Interestingly, Dreon et al. found a positive correlation between SFA intake and large, buoyant LDL particles, with no such association with poly- or mono-unsaturated fatty acids [9]. Another study found that substituting saturated fat with carbohydrates resulted in smaller and denser LDL particles [10]. Thus, the benefit of reducing the intake of foods with high amounts of saturated fat is highly dependent on what is eaten instead.

Cheese is a dairy product with a high content of saturated fat. Therefore, it is a common perception that cheese increases plasma LDL-C and in turn CVD risk. However, human intervention studies show that cheese has a neutral effect on plasma cholesterol levels when compared with butter intake [11]. Likewise, prospective studies found no association between cheese intake and CVD risk [12, 13] or increased risk of all-cause mortality [14]. One of the explanations behind the findings from prospective studies might be that saturated fat in cheese results in larger LDL particle size. This has, however not yet been confirmed in a clinical trial.

The primary objective of the current study was to compare the effect of cheese intake with different fat content and an iso-caloric amount of carbohydrate-rich foods on LDL particle size distribution in a metabolically vulnerable study population. Based on studies showing that the increase in LDL-C induced by saturated fat results in a higher proportion of larger and less atherogenic LDL particles [15-18], we hypothesized that intake of regular-fat cheese would be associated with larger LDL particles compared to reduced-fat cheese and a carbohydrate-rich control diet.

\section{Methods}

\section{Study design}

The present study was part of a larger study, which has been described in detail elsewhere [19]. In brief, 164 subjects (18-70 years of age) were recruited for a $12-$ wk randomized, parallel intervention, with a 2 -wk run-in period. Subjects were allocated to three intervention groups; regular-fat cheese (REG), reduced-fat cheese (RED), or non-cheese/carbohydrate (CHO). Fasting blood samples were drawn after the 2-wk run-in period at baseline (wk 0) and after the 12-wk intervention period. The study was carried out at the Department of Nutrition, Exercise and Sports, Faculty of Sciences, University of Copenhagen, Frederiksberg, Denmark, from February 2014 to May 2015 and was approved by the Municipal Ethical Committee of Copenhagen (H-4-2013-099). All of the subjects gave their informed consent in writing after receiving written and oral information about the study.

\section{Subjects}

In this sub-study, EDTA plasma was collected at wk. 0 and wk. 12 from the 164 subjects included in the main intervention. However, due to technical issues, only blood samples collected from 85 subjects were stored properly and could be used for analysis in this sub-study.

Inclusion criteria were $18-70$ y of age, BMI (in $\mathrm{kg} / \mathrm{m}^{2}$ ) of 18.5-37.5, waist circumference $>80 \mathrm{~cm}$ for women and $>94 \mathrm{~cm}$ for men, and $\geq 1$ additional established risk factor for the MetS; systolic blood pressure $>130 \mathrm{mmHg}$ and/or diastolic blood pressure $>85 \mathrm{mmHg}$, triacylglycerols $>1.7 \mathrm{mmol} / \mathrm{l}$, HDL cholesterol $<1.00 \mathrm{mmol} / \mathrm{l}$ for men and $<1.3 \mathrm{mmol} / \mathrm{l}$ for women, and/or glucose $>$ $5.6 \mathrm{mmol} / \mathrm{l}$. Exclusion criteria were chronic diseases (known T2D, CVD, or other chronic diseases that could affect the study outcome), milk allergy, the use of prescription medicine that could affect the results of the study (e.g., lipid-lowering agents), $10 \mathrm{~h}$ of strenuous physical activity/wk., drug and alcohol abuse, blooddonation,1 mo before study commencement or during the study period, simultaneous participation in other clinical studies, pregnant or lactating woman or women who were planning to become pregnant during the intervention, or inability to comply with the procedures required by the protocol.

Subjects (62 women and 23 men) with $\geq 2$ metabolic syndrome risk factors had a mean BMI of $28.7 \pm 3.6 \mathrm{~kg} /$ $\mathrm{m}^{2}$ and a mean age of $54.0 \pm 12.8 \mathrm{y}$. Baseline characteristics of the 85 subjects included in this study are listed in Table 1.

\section{Experimental diets}

The energy content and macronutrient distribution of the three test foods have been described in detail elsewhere [19]. In short, subjects in the REG and RED groups were provided with equal amounts of regular-fat Danbo (Riberhus, 25\% fat, Arla, Denmark) and cheddar 
Table 1 Subject baseline characteristics ${ }^{\mathrm{a}}$

\begin{tabular}{|c|c|c|c|}
\hline & REG $(n=30)$ & $\operatorname{RED}(n=26)$ & $\mathrm{CHO}(n=29)$ \\
\hline \multicolumn{4}{|l|}{$\operatorname{Sex}[n(\%)]$} \\
\hline Women & $21(70)$ & $21(81)$ & $20(69)$ \\
\hline Men & $9(30)$ & $5(19)$ & $9(31)$ \\
\hline Age (y) & $54.8 \pm 13.7$ & $51.8 \pm 13.4$ & $55.0 \pm 11.6$ \\
\hline Weight (kg) & $84.2 \pm 14.3$ & $84.5 \pm 11.2$ & $84.3 \pm 16.5$ \\
\hline BMI $\left(\mathrm{kg} / \mathrm{m}^{2}\right)$ & $29.3 \pm 3.6$ & $28.4 \pm 3.0$ & $28.4 \pm 4.0$ \\
\hline Waist circumference (cm) & $98.1 \pm 11.6$ & $96.7 \pm 10.3$ & $96.9 \pm 10.9$ \\
\hline Smoking [n (\%)] & $1(3)$ & $2(7)$ & $1(3)$ \\
\hline Energy requirement $(\mathrm{MJ} / \mathrm{d})$ & $10.3 \pm 1.9$ & $10.3 \pm 1.8$ & 10.2 \\
\hline Systolic blood pressure (mmHG) & $133.2 \pm 16.3$ & $129.7 \pm 14.1$ & $128.0 \pm 16.8$ \\
\hline Diastolic blood pressure (mmHG) & $85.7 \pm 9.1$ & $82.8 \pm 8.6$ & $84.0 \pm 8.3$ \\
\hline
\end{tabular}

${ }^{a}$ Values are means \pm SDs unless otherwise indicated. $n=85$. CHO carbohydrate control, $R E D$ reduced-fat cheese, REG regular-fat cheese

(Sharp Cheddar, 32\% fat, Lactalis, Scotland), and reduced-fat Danbo (Riberhus,13\% fat, Arla, Denmark) and cheddar (Sharp Cheddar, 16\% fat, Lactalis, Scotland), respectively. In the $\mathrm{CHO}$ group, cheese was replaced with white wheat bread (Kohberg, Denmark) and sugar-sweetened jam (Fynbo, Denmark). Subjects in all three groups were also provided with $250 \mathrm{ml}$ of skimmed milk $(0.1 \%$ fat, Arla, Denmark $)$ per day throughout the intervention. No other dairy products were allowed during the intervention. The daily amounts of cheese provided corresponded to $80 \mathrm{~g} / \mathrm{d}$ per $10 \mathrm{MJ}$, while the daily amounts of bread and jam corresponding to $90 \mathrm{~g} / \mathrm{d}$ and $25 \mathrm{~g} / \mathrm{d}$ per $10 \mathrm{MJ}$, respectively.

\section{Dietary records}

In order to provide information about dietary intake during the intervention, subjects completed a 3-d dietary food records at wk. 0 and wk. 12. Two week-days and one weekend day were included in the dietary record to take any differences in nutrient intake during weekdays and weekend days into account.

\section{Analytic procedures}

\section{${ }^{1} \mathrm{H}$ NMR lipoprotein subclass analysis}

Serum samples, stored in EDTA containing tubes, were prepared and measured according to Bruker's sample preparation standard operating procedures (SOPs) and In Vitro Diagnostics research (IVDr) platform, which allow highly standardized and reproducible NMR measurements of biofluids, as reported previously [20]. The spectrometer was a Bruker Avance-III 600 spectrometer (Bruker Biospin Gmbh, Rheinstetten, Germany) operating at a proton frequency of $600.13 \mathrm{MHz}(14.1 \mathrm{~T})$, equipped with a double tuned broadband inverse (BBI) probe for 5-mm sample tubes. Bruker IVDr Lipoprotein Subclass Analysis (B.I.-LISA) was then used to analyze the resulted ${ }^{1} \mathrm{H}$ NMR spectra and calculate lipoproteins subclasses. In brief, this platform uses a regression model that is developed using ultracentrifugation results of a training dataset, which allows for prediction of the concentrations of the lipoproteins from the ${ }^{1} \mathrm{H}$ NMR spectra of new plasma samples without any further need for ultra-centrifugation [21, 22]. This model provides information on main lipoprotein classes, including very low density lipoprotein (VLDL), intermediate density lipoprotein (IDL), LDL, and high density lipoprotein (HDL), as well as the six VLDL subclasses (VLDL-1 to VLDL-6), six LDL subclasses (LDL-1 to LDL-6), and four HDL subclasses (HDL-1 to HDL-4). Subclasses were sorted according to their increasing density and decreasing size in ascending order, respectively. Compositional information of main -and subclasses consists of lipids, i.e., cholesterol, free cholesterol, triglycerides, phospholipids and apolipoproteins; Apo-A1, Apo-A2 and Apo-B in mg/dl unit. Moreover, information on particle numbers for VLDL, IDL and LDL main classes, and VLDL and LDL subclasses were also obtained from B.I.-LISA, in $\mathrm{nmol} / \mathrm{L}$ unit.

\section{Statistical analysis}

All statistical analyses were performed using $\mathrm{R}$ ( $\mathrm{R}$ Core Team, 2015) [23]. Linear mixed models were used to evaluate the effect of the intervention on all outcomes. Baseline outcome values were included as covariates. Adjustments for age, sex, BMI, and changes in body fat percent (from wk. 0 to wk. 12) were also included as fixed effects. As a significant effect of sex was observed, separate sub-analysis for men and women were carried out for all outcomes. Differences between periods were captured by means of random effects. For each outcome two pairwise comparisons were evaluated: REG versus RED and REG versus $\mathrm{CHO}$, using post hoc t-test based on the linear mixed models; $p$-values were adjusted for multiplicity [24]. Model checking of assumptions of 
homogeneity of variance and normal distribution was carried out by means of residual and normal probability plots. Results are presented as means \pm SEMs. A significance level of 0.05 was used.

\section{Results}

\section{Anthropometrics}

Changes in mean anthropometric measures, body composition, and blood pressure are shown in Table 2. There were no significant differences in body weight, fat mass, lean body mass, waist circumference, or blood pressure between REG and RED diets or between the REG and CHO diets (all $P \geq 0.05$ ).

\section{Lipoprotein particle number}

Changes from baseline as well as differences between groups for total VLDL-P and its subclasses, IDL-P, and LDL-P and its subclasses are shown in Table 3. Overall, there were no significant differences for these outcomes between the REG diet and RED diet or between REG and $\mathrm{CHO}$ diet (all $P \geq 0.16$ ). The gender sub analysis showed similar results in women (all $P \geq$ 0.17), (Table 4). However, the gender sub analysis showed a decrease in LDL-P in men on the REG diet compared to the RED diet $(-223.2 \pm 91.1 \mathrm{nmol} / \mathrm{l}, P=$ 0.01 ) (Table 5). The decrease in LDL-P in men was primarily due to a lower number of medium-sized LDL particles $(-128.5 \pm 51.8 \mathrm{nmol} / \mathrm{l}, P=0.01)$. Ratios of LDL-C:HDL-C and ApoB:ApoA-1 were significantly reduced in men on the REG diet compared with the RED diet $(-0.53 \pm 0.13, P=0.0007$ and $0.09 \pm 0.03, P$ $=0.009$, respectively), but did not differ from that of the $\mathrm{CHO}$ diet (Table 5).

\section{Cholesterol concentration in lipoprotein subclasses}

Total VLDL-C and LDL-C did not differ between the diets (all $P \geq 0.2$ ) (Table 3). However, the gender sub analysis in men showed a reduction of total LDL-C (-19.4 $\pm 9.5 \mathrm{mg} / \mathrm{dl}, P=0.04)$. The decrease in total LDL-C in men was due to a decreased concentration of cholesterol in the medium-sized $\left(\mathrm{LDL}_{3+4}\right)$ and small-sized $\left(\mathrm{LDL}_{5+}\right.$ 6) LDL particles in the REG diet compared to the RED diet $(-11.3 \pm 5.2 \mathrm{mg} / \mathrm{dl}, P=0.03$ and $-10.1 \pm 5.0 \mathrm{mg} / \mathrm{dl}$, $P=0.04$, respectively) (Table 5). Total HDL-C was higher on the REG diet compared with the CHO diet (3.5 \pm $1.6 \mathrm{mg} / \mathrm{dl}, P=0.03$ ) (Table 3). The increase in total HDL-C was due to a significantly higher concentration of cholesterol in the smaller HDL particles $\left(\mathrm{HDL}_{3+4}\right)$ on the REG diet compared with the CHO diet $(1.9 \pm$ $0.8 \mathrm{mg} / \mathrm{dl}, P=0.02$ ). The gender sub analysis in women showed similar results with an increase in total HDL-C and cholesterol in the smaller HDL particles $\left(\mathrm{HDL}_{3+4)}\right.$ on the REG diet compared to the $\mathrm{CHO}$ diet $(4.8 \pm$ $2.1 \mathrm{mg} / \mathrm{dl}, \quad P=0.02$ and $2.9 \pm 1.0 \mathrm{mg} / \mathrm{dl}, \quad P=0.006$, respectively) (Table 4 ). In contrast, the gender sub analysis in men showed no differences in HDL-C between the diets (Table 5).

\section{Dietary records}

Results from the dietary records are shown in Table 6 . Energy intake did not differ between groups, although subjects in the REG group tended to have a higher energy intake compared with the $\mathrm{CHO}$ group $(P=0.08)$. Fat intake (in $g$ and percentage of energy) was higher during the REG intervention than during the $\mathrm{CHO}(P<$ 0.001 ) diets, but did not differ between the REG and RED diets. There was a higher intake of saturated fat during the REG diet compared to the RED and $\mathrm{CHO}$

Table 2 Fasting values of anthropometric measurements, body composition and blood pressure at week 12 and changes from baseline $^{a}$

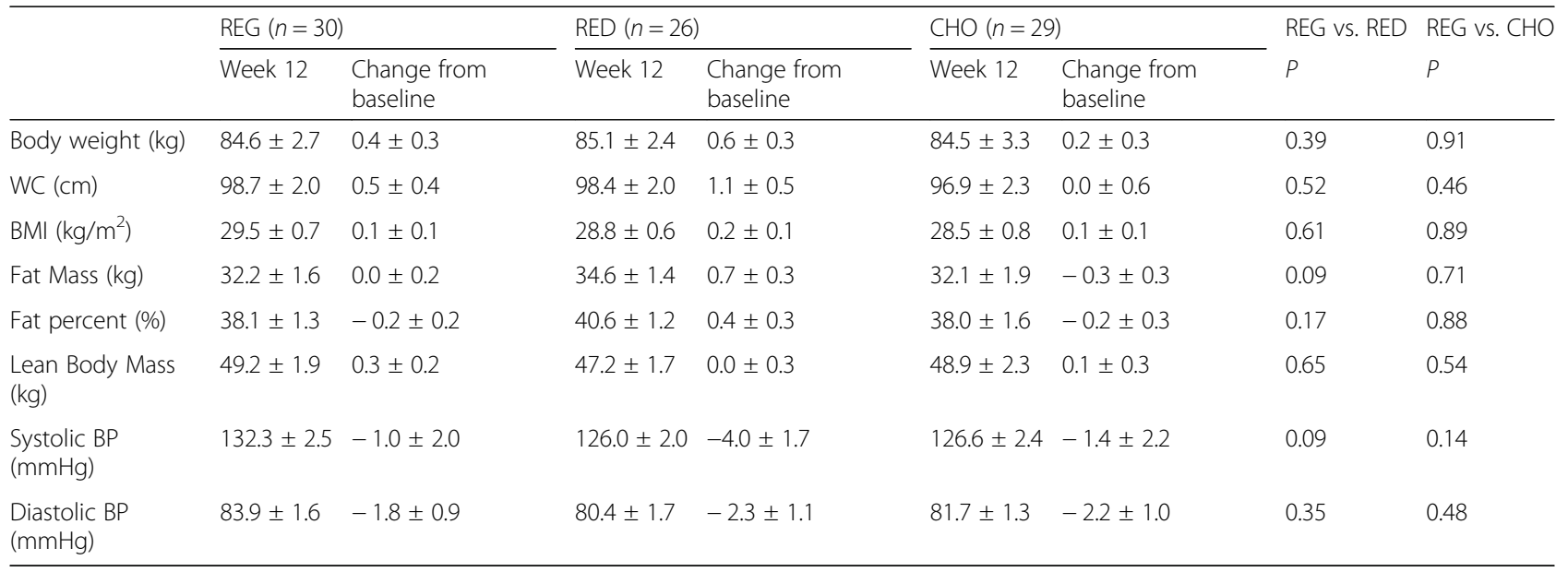

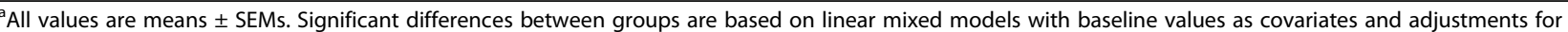
age, sex, BMI, and change in body fat. Pairwise comparisons were made by using a post hoc $t$ test on the linear mixed model with $P$ values adjusted for multiplicity. BP blood pressure, $C H O$ carbohydrate control, RED reduced-fat cheese, REG regular-fat cheese, WC waist circumference 
Table 3 Lipoprotein particle number and cholesterol content at wk. 12 and changes from baseline in men and women ${ }^{\mathrm{a}}$

\begin{tabular}{|c|c|c|c|c|c|c|c|c|}
\hline & \multicolumn{2}{|l|}{$\operatorname{REG}(n=30)$} & \multicolumn{2}{|l|}{$\operatorname{RED}(n=26)$} & \multicolumn{2}{|l|}{$\mathrm{CHO}(n=29)$} & \multirow{2}{*}{$\begin{array}{l}\text { REG vs. } \\
\text { RED } \\
P\end{array}$} & \multirow{2}{*}{$\begin{array}{l}\text { REG vs. } \\
\mathrm{CHO} \\
P\end{array}$} \\
\hline & Week 12 & $\begin{array}{l}\text { Change from } \\
\text { baseline }\end{array}$ & Week 12 & $\begin{array}{l}\text { Change from } \\
\text { baseline }\end{array}$ & Week 12 & $\begin{array}{l}\text { Change from } \\
\text { baseline }\end{array}$ & & \\
\hline$\overline{V L D L-P}(\mathrm{nmol} / \mathrm{l})^{2}$ & $148.4 \pm 14.1$ & $-3.6 \pm 15.3$ & $129.5 \pm 9.4$ & $-6.0 \pm 8.8$ & $126.1 \pm 13.8$ & $3.4 \pm 6.7$ & 0.56 & 0.67 \\
\hline IDL-P (nmol/L) & $73.3 \pm 6.9$ & $-4.5 \pm 6.9$ & $68.5 \pm 6.5$ & $-6.1 \pm 5.0$ & $68.2 \pm 7.0$ & $2.1 \pm 4.3$ & 0.62 & 0.81 \\
\hline \multicolumn{9}{|l|}{ LDL-P (nmol/l) } \\
\hline Total & $1322 \pm 60.0$ & $26.2 \pm 41.3$ & $1265 \pm 78.8$ & $7.9 \pm 50.2$ & $1363 \pm 55.5$ & $-2.9 \pm 39.1$ & 0.43 & 0.99 \\
\hline $\operatorname{LDL}_{1+2^{b}}$ & $415.9 \pm 21.4$ & $22.2 \pm 15.1$ & $444.2 \pm 23.0$ & $-13.3 \pm 19.3$ & $453.2 \pm 22.4$ & $-29.3 \pm 14.7$ & 0.82 & 0.16 \\
\hline $\operatorname{LDL}_{3+4}{ }^{\mathrm{b}}$ & $403.2 \pm 20.6$ & $9.9 \pm 22.4$ & $414.9 \pm 31.6$ & $15.9 \pm 19.5$ & $403.3 \pm 22.2$ & $-10.8 \pm 18.1$ & 0.98 & 0.76 \\
\hline $\mathrm{LDL}_{5+6^{\mathrm{b}}}$ & $487.7 \pm 43.1$ & $-12.7 \pm 20.5$ & $391.1 \pm 43.6$ & $-7.7 \pm 25.7$ & $479.6 \pm 49.3$ & $32.0 \pm 19.0$ & 0.39 & 0.35 \\
\hline \multicolumn{9}{|l|}{ VLDL-C (mg/dl) } \\
\hline Total $^{b}$ & $16.5 \pm 2.2$ & $-0.5 \pm 2.4$ & $13.2 \pm 1.6$ & $-1.3 \pm 1.3$ & $12.8 \pm 2.4$ & $0.7 \pm 1.2$ & 0.47 & 0.68 \\
\hline $\mathrm{VLDL}_{1+2}$ & $7.3 \pm 1.2$ & $0.7 \pm 1.1$ & $4.9 \pm 0.9$ & $-0.5 \pm 0.6$ & $5.0 \pm 1.3$ & $0.1 \pm 0.1$ & 0.26 & 0.56 \\
\hline $\mathrm{VLDL}_{3+4}{ }^{\mathrm{b}}$ & $6.7 \pm 1.0$ & $-1.2 \pm 1.3$ & $5.6 \pm 0.7$ & $-1.0 \pm 0.7$ & $5.4 \pm 1.0$ & $-0.2 \pm 0.5$ & 0.67 & 0.87 \\
\hline $\operatorname{VLDL}_{5+6^{b}}$ & $2.1 \pm 0.1$ & $-0.1 \pm 0.1$ & $2.0 \pm 0.1$ & $0.0 \pm 0.1$ & $2.0 \pm 0.1$ & $0.7 \pm 0.7$ & 0.96 & 0.68 \\
\hline $\mathrm{IDL}-\mathrm{C}(\mathrm{mg} / \mathrm{dl})$ & $7.0 \pm 1.1$ & $-0.2 \pm 0.9$ & $6.7 \pm 1.1$ & $-1.5 \pm 1.3$ & $7.1 \pm 1.3$ & $0.1 \pm 0.7$ & 0.28 & 0.81 \\
\hline \multicolumn{9}{|l|}{ LDL-C (mg/dl) } \\
\hline Total & $118.2 \pm 5.4$ & $3.7 \pm 4.4$ & $117.3 \pm 7.3$ & $3.8 \pm 4.9$ & $122.6 \pm 4.5$ & $-2.6 \pm 3.9$ & 0.69 & 0.70 \\
\hline $\mathrm{LDL}_{1+2} \mathrm{~b}^{\mathrm{b}}$ & $42.8 \pm 2.5$ & $2.7 \pm 1.7$ & $46.6 \pm 2.6$ & $-0.5 \pm 2.3$ & $47.2 \pm 2.4$ & $-3.2 \pm 1.9$ & 0.51 & 0.19 \\
\hline $\mathrm{LDL}_{3+4}{ }^{\mathrm{b}}$ & $38.2 \pm 2.2$ & $0.9 \pm 2.1$ & $40.0 \pm 3.1$ & $2.3 \pm 2.1$ & $38.7 \pm 2.2$ & $-1.7 \pm 1.8$ & 0.72 & 0.57 \\
\hline $\mathrm{LDL}_{5+6^{b}}$ & $36.2 \pm 3.1$ & $-0.5 \pm 1.4$ & $29.6 \pm 3.4$ & $0.2 \pm 2.0$ & $35.7 \pm 3.5$ & $2.1 \pm 1.5$ & 0.88 & 0.21 \\
\hline \multicolumn{9}{|l|}{$\mathrm{HDL}-\mathrm{C}(\mathrm{mg} / \mathrm{dl})$} \\
\hline Total & $56.0 \pm 2.9$ & $2.2 \pm 1.0$ & $56.5 \pm 2.5$ & $2.4 \pm 1.3$ & $55.9 \pm 2.3$ & $-0.6 \pm 1.3$ & 0.84 & 0.03 \\
\hline $\mathrm{HDL}_{1+2} \mathrm{~b}^{\mathrm{b}}$ & $27.1 \pm 2.7$ & $1.0 \pm 0.8$ & $27.5 \pm 2.1$ & $0.6 \pm 1.0$ & $28.6 \pm 2.0$ & $0.1 \pm 1.1$ & 0.68 & 0.23 \\
\hline $\mathrm{HDL}_{3+4}{ }^{\mathrm{b}}$ & $29.4 \pm 0.8$ & $1.2 \pm 0.6$ & $29.4 \pm 0.9$ & $1.6 \pm 0.7$ & $27.8 \pm 0.9$ & $-0.8 \pm 0.6$ & 0.95 & 0.02 \\
\hline $\begin{array}{l}\text { LDL-C:HDL-C } \\
\text { ratio }\end{array}$ & $2.2 \pm 0.1$ & $0.0 \pm 0.1$ & $2.2 \pm 0.2$ & $0.0 \pm 0.1$ & $2.3 \pm 0.1$ & $0.0 \pm 0.1$ & 0.62 & 0.81 \\
\hline $\begin{array}{l}\text { Apo-B:Apo-A1 } \\
\text { ratio }\end{array}$ & $0.6 \pm 0.0$ & $0.0 \pm 0.0$ & $0.6 \pm 0.0$ & $0.0 \pm 0.1$ & $0.7 \pm 0.0$ & $0.0 \pm 0.0$ & 0.67 & 0.16 \\
\hline
\end{tabular}

${ }^{a}$ All values are means \pm SEMs. Statistical differences between groups are based on linear mixed models with baseline values as covariates and adjustments for age, sex, BMI and change in body fat. Pairwise comparisons were made using post hoc t-test on the linear mixed model with $p$-values adjusted for multiplicity. ${ }^{b}$ Significant sex effect observed. Abbreviations: $A$ po apolipoprotein, $C H O$ carbohydrate control, $H D L-C$ high density lipoprotein cholesterol, IDL-C intermediate density lipoprotein cholesterol, IDL-P intermediate density lipoprotein particle number, $L D L-C$ low density lipoprotein cholesterol, $L D L-P$ low density lipoprotein particle number, $R E D$ reduced-fat cheese, REG regular-fat cheese, VLDL-C very low density lipoprotein cholesterol, VLDL- $P$ very low density lipoprotein particle number

diets $(P<0.01$ and $P<0.001$, respectively). The amount of MUFAs was significantly higher with the REG diet than with the $\mathrm{CHO}$ diet $(P<0.01)$. As expected, the intake of carbohydrate was greater with the $\mathrm{CHO}$ diet than with the REG diet $(P<0.001)$.

\section{Discussion}

In the present study, we compared the effects of consuming regular-fat cheese, reduced-fat cheese and carbohydrate-rich foods for 12 wks on lipoprotein particle size distribution in a population with $\geq 2$ metabolic syndrome (MetS) risk factors. Our results demonstrated that long-term consumption of regular-fat cheese did not modify the distribution of LDL subclasses differently compared with reduced-fat cheese. The lack of differences in LDL particle size between the two cheese groups were unexpected, as the saturated fat intake in the regular-fat cheese group was significantly higher than in the reduced-fat cheese group $(33.3 \mathrm{~g} / \mathrm{d}$ vs. $27.2 \mathrm{~g} / \mathrm{d}$ ). However, it can be speculated that the differences in saturated fat were insufficient to elicit a significant shift towards larger LDL particles in the regular-fat cheese group, as overall fat intake did not differ between the two groups. Furthermore, it cannot be ruled out that the effect of fat in cheese on LDL particle size might be modulated by constituents in the cheese matrix. The high content of calcium in cheese has been suggested to modulate the effect of saturated fat on LDL-C 
Table 4 Lipoprotein particle number and cholesterol content at wk. 12 and changes from baseline in women ${ }^{\mathrm{a}}$

\begin{tabular}{|c|c|c|c|c|c|c|c|c|}
\hline & \multicolumn{2}{|l|}{$\operatorname{RED}(n=21)$} & \multicolumn{2}{|l|}{$\operatorname{RED}(n=21)$} & \multicolumn{2}{|l|}{$\mathrm{CHO}(n=20)$} & \multirow{2}{*}{$\begin{array}{l}\text { REG vs. RED } \\
P\end{array}$} & \multirow{2}{*}{$\begin{array}{l}\text { REG vs. CHO } \\
P\end{array}$} \\
\hline & Week 12 & $\begin{array}{l}\text { Change from } \\
\text { baseline }\end{array}$ & Week 12 & $\begin{array}{l}\text { Change from } \\
\text { baseline }\end{array}$ & Week 12 & $\begin{array}{l}\text { Change from } \\
\text { baseline }\end{array}$ & & \\
\hline VLDL-P (nmol/l) & $135.6 \pm 13.5$ & $-11.2 \pm 20.0$ & $126.7 \pm 10.6$ & $-10.4 \pm 10.3$ & $104.4 \pm 13.3$ & $-6.4 \pm 7.0$ & 0.59 & 0.25 \\
\hline IDL-P (nmol/L) & $68.8 \pm 6.1$ & $-4.9 \pm 9.3$ & $68.5 \pm 6.8$ & $-7.6 \pm 5.7$ & $63.7 \pm 7.2$ & $1.3 \pm 5.5$ & 0.75 & 0.91 \\
\hline \multicolumn{9}{|l|}{ LDL-P (nmol/l) } \\
\hline Total & $1343.0 \pm 57.4$ & $72.4 \pm 53.1$ & $1238.3 \pm 81.0$ & $-30.9 \pm 49.4$ & $1359.7 \pm 71.9$ & $11.3 \pm 52.7$ & 0.08 & 0.83 \\
\hline $\mathrm{LDL}_{1+2}$ & $449.9 \pm 24.1$ & $31.0 \pm 19.6$ & $459.9 \pm 25.0$ & $-14.2 \pm 23.0$ & $497.4 \pm 23.5$ & $-22.3 \pm 21.0$ & 0.41 & 0.68 \\
\hline $\mathrm{LDL}_{3+4}$ & $471.6 \pm 19.2$ & $45.2 \pm 25.5$ & $408.4 \pm 35.1$ & $-0.5 \pm 17.7$ & $422.8 \pm 26.2$ & $1.2 \pm 24.1$ & 0.24 & 0.51 \\
\hline $\mathrm{LDL}_{5+6}$ & $451.8 \pm 42.6$ & $-9.1 \pm 25.9$ & $354.5 \pm 37.7$ & $31.4 \pm 23.6$ & $407.7 \pm 47.3$ & $25.2 \pm 18.8$ & 0.17 & 0.25 \\
\hline \multicolumn{9}{|l|}{ VLDL-C (mg/dl) } \\
\hline Total & $13.8 \pm 2.0$ & $-1.9 \pm 3.0$ & $12.7 \pm 1.8$ & $-2.0 \pm 1.6$ & $9.1 \pm 2.1$ & $-0.9 \pm 1.2$ & 0.65 & 0.30 \\
\hline $\mathrm{VLDL}_{1+2}$ & $5.8 \pm 1.2$ & $0.1 \pm 1.2$ & $4.5 \pm 1.0$ & $-0.8 \pm 0.8$ & $2.9 \pm 1.1$ & $-0.4 \pm 0.6$ & 0.31 & 0.21 \\
\hline $\mathrm{VLDL}_{3+4}$ & $5.6 \pm 0.8$ & $-1.8 \pm 1.7$ & $5.6 \pm 0.9$ & $-1.3 \pm 0.9$ & $4.1 \pm 0.9$ & $-0.7 \pm 0.5$ & 0.94 & 0.51 \\
\hline $\operatorname{VLDL}_{5+6}$ & $2.0 \pm 0.1$ & $-0.1 \pm 0.2$ & $2.1 \pm 0.1$ & $0.0 \pm 0.1$ & $1.8 \pm 0.1$ & $0.0 \pm 0.1$ & 0.62 & 0.83 \\
\hline IDL-C (mg/dl) & $5.9 \pm 0.9$ & $-0.6 \pm 1.1$ & $7.3 \pm 1.3$ & $-1.6 \pm 1.6$ & $6.1 \pm 1.2$ & $-0.2 \pm 0.8$ & 0.83 & 0.60 \\
\hline \multicolumn{9}{|l|}{ LDL-C (mg/dl) } \\
\hline Total & $121.3 \pm 5.7$ & $8.3 \pm 5.5$ & $114.9 \pm 7.9$ & $0.4 \pm 4.8$ & $124.6 \pm 6.0$ & $-0.3 \pm 5.2$ & 0.21 & 0.79 \\
\hline $\mathrm{LDL}_{1+2}$ & $46.4 \pm 2.9$ & $3.4 \pm 2.2$ & $48.2 \pm 2.8$ & $-0.6 \pm 2.7$ & $51.9 \pm 2.5$ & $-2.3 \pm 2.2$ & 0.60 & 0.74 \\
\hline $\mathrm{LDL}_{3+4}$ & $40.0 \pm 2.2$ & $3.9 \pm 2.3$ & $39.4 \pm 3.4$ & $0.8 \pm 1.9$ & $40.9 \pm 2.6$ & $-0.4 \pm 2.4$ & 0.37 & 0.53 \\
\hline $\mathrm{LDL}_{5+6}$ & $33.7 \pm 3.2$ & $-0.2 \pm 1.7$ & $26.6 \pm 3.0$ & $-1.7 \pm 1.7$ & $30.7 \pm 3.5$ & $2.0 \pm 1.5$ & 0.19 & 0.29 \\
\hline \multicolumn{9}{|l|}{$\mathrm{HDL}-\mathrm{C}(\mathrm{mg} / \mathrm{dl})$} \\
\hline Total & $61.2 \pm 3.2$ & $2.8 \pm 1.2$ & $57.9 \pm 2.8$ & $2.7 \pm 1.4$ & $59.2 \pm 2.8$ & $-1.3 \pm 1.8$ & 0.73 & 0.02 \\
\hline $\mathrm{HDL}_{1+2}$ & $31.7 \pm 3.1$ & $1.1 \pm 1.0$ & $28.9 \pm 2.4$ & $0.9 \pm 1.1$ & $32.1 \pm 2.4$ & $-0.3 \pm 1.5$ & 0.77 & 0.21 \\
\hline $\mathrm{HDL}_{3+4}$ & $30.1 \pm 1.0$ & $1.6 \pm 0.8$ & $29.3 \pm 1.0$ & $1.6 \pm 0.7$ & $27.7 \pm 1.0$ & $-1.2 \pm 0.7$ & 0.63 & 0.006 \\
\hline $\begin{array}{l}\text { LDL-C:HDL-C } \\
\text { ratio }\end{array}$ & $2.1 \pm 0.1$ & $0.1 \pm 0.1$ & $2.1 \pm 0.2$ & $-0.1 \pm 0.1$ & $2.2 \pm 0.1$ & $0.1 \pm 0.1$ & 0.20 & 0.69 \\
\hline $\begin{array}{l}\text { Apo-B:Apo-A1 } \\
\text { ratio }\end{array}$ & $0.6 \pm 0.0$ & $0.0 \pm 0.0$ & $0.6 \pm 0.0$ & $0.0 \pm 0.0$ & $0.6 \pm 0.0$ & $0.0 \pm 0.0$ & 0.23 & 0.19 \\
\hline
\end{tabular}

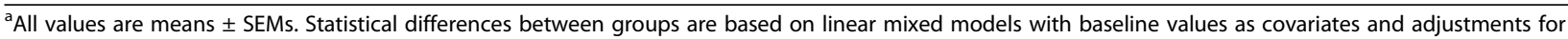
age, BMI and change in body fat. Pairwise comparisons were made using post hoc t-test on the linear mixed model with p-values adjusted for multiplicity. Abbreviations: Apo apolipoprotein, $C H O$ carbohydrate control, $H D L-C$ high density lipoprotein cholesterol, IDL-C intermediate density lipoprotein cholesterol, IDL-P intermediate density lipoprotein particle number, $L D L-C$ low density lipoprotein cholesterol, $L D L-P$ low density lipoprotein particle number, $R E D$ reduced-fat cheese, REG regular-fat cheese, VLDL-C very low density lipoprotein cholesterol, VLDL-P very low density lipoprotein particle number

concentrations by increasing fecal fat excretion. Measurements of fecal fat and energy excretion in this study could have added to the mechanistic understanding of the observed findings. Our finding is in accordance with a recently published study showing that despite a $6 \%$ higher saturated fat content in a high-fat dairy DASH diet compared with a low-fat dairy DASH diet, no differences in LDL cholesterol or any of the LDL subclasses was observed in a population of both men and women [25]. In the present study, however, significant gender-specific differences in regard to LDL subfractions were observed. In men, total LDL particle number was significantly reduced following the REG diet compared with the RED diet. The decrease in total LDL particle number was primarily due to a $\sim 6 \%$ lower proportion of midsize LDL particles, while the proportion of smaller
LDL particles only tended to be reduced $(P=0.06)$. In contrast to the results obtained in men, the REG diet only tended to increase total LDL-P compared with the RED diet in women $(P=0.08)$. Our findings indicate that middle-aged men might have a more favorable lipoprotein response to regular-fat cheese compared to reduced-fat cheese than middle-aged/postmenopausal women, although this needs to be verified in further studies with larger sample size. However, LDL particle size distribution depends on other factors than gender and genetics alone, including, hormonal status (at menopause, LDL particle size distribution shift towards sdLDL) [26], overall lifestyle, and dietary habits. These factors can be difficult to adjust for in a study with "free living" individuals. Thus, it cannot be ruled out that the gender differences in response to the test foods in the 
Table 5 Lipoprotein particle number and cholesterol content at wk. 12 and changes from baseline in men ${ }^{a}$

\begin{tabular}{|c|c|c|c|c|c|c|c|c|}
\hline & \multicolumn{2}{|l|}{ REG $(n=9)$} & \multicolumn{2}{|l|}{$\operatorname{RED}(n=5)$} & \multicolumn{2}{|l|}{$\mathrm{CHO}(n=9)$} & \multirow{2}{*}{$\begin{array}{l}\text { REG vs. } \\
\text { RED } \\
P\end{array}$} & \multirow{2}{*}{$\begin{array}{l}\text { REG vs. } \\
\mathrm{CHO} \\
P\end{array}$} \\
\hline & Week 12 & $\begin{array}{l}\text { Change from } \\
\text { baseline }\end{array}$ & Week 12 & $\begin{array}{l}\text { Change from } \\
\text { baseline }\end{array}$ & Week 12 & $\begin{array}{l}\text { Change from } \\
\text { baseline }\end{array}$ & & \\
\hline $\begin{array}{l}\text { VLDL-P (nmol/ } \\
\text { I) }\end{array}$ & $178.3 \pm 34.0$ & $14.3 \pm 21.1$ & $141.3 \pm 21.7$ & $12.5 \pm 14.8$ & $174.5 \pm 28.2$ & $25.2 \pm 13.0$ & 0.56 & 0.12 \\
\hline IDL-P (nmol/L) & $83.9 \pm 18.5$ & $-3.4 \pm 8.2$ & $68.2 \pm 19.7$ & $0.1 \pm 10.9$ & $78.0 \pm 16.0$ & $3.8 \pm 7.2$ & 0.61 & 0.24 \\
\hline \multicolumn{9}{|l|}{ LDL-P (nmol/l) } \\
\hline Total & $1275.3 \pm 154.4$ & $-81.7 \pm 45.5$ & $1381.7 \pm 244.9$ & $171.0 \pm 150.1$ & $1372.0 \pm 86.3$ & $-34.6 \pm 48.5$ & 0.01 & 0.68 \\
\hline $\mathrm{LDL}_{1+2}$ & $336.4 \pm 31.8$ & $1.6 \pm 21.3$ & $378.1 \pm 51.9$ & $-9.6 \pm 31.3$ & $355.0 \pm 31.3$ & $-44.8 \pm 8.6$ & 0.45 & 0.05 \\
\hline $\mathrm{LDL}_{3+4}$ & $369.5 \pm 53.0$ & $-72.4 \pm 32.2$ & $441.8 \pm 79.5$ & $84.5 \pm 65.9$ & $359.9 \pm 40.3$ & $-37.3 \pm 21.8$ & 0.01 & 0.53 \\
\hline $\mathrm{LDL}_{5+6}$ & $571.4 \pm 103.3$ & $-21.1 \pm 33.9$ & $544.8 \pm 156.7$ & $91.8 \pm 81.7$ & $639.2 \pm 104.8$ & $47.1 \pm 46.2$ & 0.06 & 0.12 \\
\hline \multicolumn{9}{|l|}{ VLDL-C (mg/dl) } \\
\hline Total & $22.7 \pm 5.4$ & $2.7 \pm 4.1$ & $15.1 \pm 3.4$ & $1.5 \pm 1.7$ & $21.0 \pm 5.1$ & $4.1 \pm 2.7$ & 0.97 & 0.22 \\
\hline $\mathrm{VLDL}_{1+2}$ & $10.6 \pm 2.6$ & $1.9 \pm 2.5$ & $6.7 \pm 2.1$ & $0.9 \pm 1.0$ & $9.6 \pm 2.9$ & $3.0 \pm 1.6$ & 0.79 & 0.28 \\
\hline $\operatorname{VLDL}_{3+4}$ & $9.3 \pm 2.7$ & $0.3 \pm 1.6$ & $5.7 \pm 1.4$ & $0.4 \pm 1.4$ & $8.3 \pm 2.4$ & $1.1 \pm 1.2$ & 0.67 & 0.19 \\
\hline $\operatorname{VLDL}_{5+6}$ & $2.2 \pm 0.4$ & $0.1 \pm 0.2$ & $1.8 \pm 0.1$ & $0.0 \pm 0.3$ & $2.4 \pm 0.3$ & $0.1 \pm 0.2$ & 0.76 & 0.72 \\
\hline IDL-C (mg/dl) & $9.6 \pm 3.0$ & $0.7 \pm 1.6$ & $4.3 \pm 1.5$ & $-1.3 \pm 2.3$ & $9.4 \pm 3.2$ & $0.8 \pm 1.5$ & 0.69 & 0.55 \\
\hline \multicolumn{9}{|l|}{ LDL-C (mg/dl) } \\
\hline Total & $111.0 \pm 12.8$ & $-6.9 \pm 5.8$ & $127.1 \pm 20.1$ & $18.2 \pm 15.7$ & $118.3 \pm 6.1$ & $-7.8 \pm 5.1$ & 0.04 & 0.82 \\
\hline $\mathrm{LDL}_{1+2}$ & $34.3 \pm 3.5$ & $1.0 \pm 2.5$ & $40.1 \pm 6.0$ & $0.0 \pm 4.0$ & $36.8 \pm 3.5$ & $-5.1 \pm 1.2$ & 0.88 & 0.03 \\
\hline $\mathrm{LDL}_{3+4}$ & $33.9 \pm 5.1$ & $-6.2 \pm 3.5$ & $42.5 \pm 7.5$ & $8.4 \pm 7.2$ & $33.7 \pm 4.1$ & $-4.5 \pm 2.3$ & 0.03 & 0.76 \\
\hline $\mathrm{LDL}_{5+6}$ & $42.1 \pm 7.3$ & $-1.2 \pm 2.3$ & $42.1 \pm 11.7$ & $8.6 \pm 6.8$ & $47.0 \pm 7.0$ & $2.6 \pm 3.4$ & 0.04 & 0.29 \\
\hline \multicolumn{9}{|l|}{ HDL-C (mg/dl) } \\
\hline Total & $43.8 \pm 3.7$ & $1.0 \pm 2.0$ & $50.8 \pm 5.4$ & $1.0 \pm 3.0$ & $48.5 \pm 2.5$ & $1.0 \pm 1.3$ & 0.72 & 0.88 \\
\hline $\mathrm{HDL}_{1+2}$ & $16.4 \pm 3.4$ & $0.6 \pm 1.4$ & $21.6 \pm 3.2$ & $-0.8 \pm 1.7$ & $20.8 \pm 2.4$ & $1.0 \pm 1.0$ & 0.09 & 0.49 \\
\hline $\mathrm{HDL}_{3+4}$ & $27.7 \pm 1.7$ & $0.4 \pm 0.8$ & $29.7 \pm 2.3$ & $1.6 \pm 1.8$ & $28.1 \pm 1.8$ & $0.1 \pm 1.0$ & 0.36 & 0.73 \\
\hline $\begin{array}{l}\text { LDL-C:HDL-C } \\
\text { ratio }\end{array}$ & $2.7 \pm 0.3$ & $-0.2 \pm 0.1$ & $2.6 \pm 0.4$ & $0.3 \pm 0.2$ & $2.5 \pm 0.2$ & $-0.2 \pm 0.1$ & 0.0007 & 0.72 \\
\hline $\begin{array}{l}\text { ApoB:ApoA1 } \\
\text { ratio }\end{array}$ & $0.7 \pm 0.1$ & $-0.1 \pm 0.0$ & $0.7 \pm 0.1$ & $0.0 \pm 0.0$ & $0.7 \pm 0.1$ & $0.0 \pm 0.0$ & 0.009 & 0.96 \\
\hline
\end{tabular}

${ }^{a}$ All values are means \pm SEMs. Statistical differences between groups are based on linear mixed models with baseline values as covariates and adjustments for age, BMI and change in body fat. Pairwise comparisons were made using post hoc t-test on the linear mixed model with $p$-values adjusted for multiplicity. Abbreviations: Apo apolipoprotein, $C H O$ carbohydrate control, $H D L-C$ high density lipoprotein cholesterol, IDL-C intermediate density lipoprotein cholesterol, IDL- $P$ intermediate density lipoprotein particle number, $L D L-C$ low density lipoprotein cholesterol, $L D L-P$ low density lipoprotein particle number, $R E D$ reduced-fat cheese, REG regular-fat cheese, VLDL-C very low density lipoprotein cholesterol, VLDL-P very low density lipoprotein particle number

current study have been influenced by these additional factors.

The saturated fat in regular-fat cheese did not result in larger LDL particles compared to the carbohydrate control, despite the significantly higher intake of saturated fat $(33.3 \mathrm{~g} / \mathrm{d}$ vs. $19.0 \mathrm{~g} / \mathrm{d})$. This was unexpected, as individuals who consume diets high in saturated fat appear to have larger LDL particles compared with diets high in carbohydrates $[9,10]$. However, most of these studies were conducted in normolipidemic men and not in a population of men and women with risk factors for the MetS as in the current study. Also, these studies are often carried out with carbohydrate restriction in the high-fat groups. However, the fact that subjects in this study were not carbohydrate-restricted in the regular-fat cheese group might explain the lack of difference.

The present study confirmed previous observations that diets with higher fat content increases HDL-C compared to carbohydrate-rich diets [27]. Overall, the concentration of total HDL-C was significantly higher for the regular-fat cheese diet compared with the carbohydrate-rich diet. The increase in total HDL-C was due to a higher concentration of cholesterol carried in the smaller HDL subclasses. Interestingly, a gender sub analysis revealed that these differences in HDL-C were only true for women. However, as this study did not have results on HDL particle size distribution, the study cannot confirm if changes in HDL-C concentrations in women were due to changes 
Table 6 Average daily consumption of energy and macronutrients for the REG, RED and CHO diet during the 12 weeks intervention $^{\mathrm{a}}$

\begin{tabular}{|c|c|c|c|c|c|}
\hline & REG $(n=27)$ & $\operatorname{RED}(n=25)$ & $\mathrm{CHO}(n=27)$ & $P_{\text {REGVs.RED }}$ & $P_{\text {REGvs.CHO }}$ \\
\hline Total energy (kJ) & $9150 \pm 356$ & $8593 \pm 557$ & $7973 \pm 437$ & 0.56 & 0.08 \\
\hline Energy density (kcal/g) & $1.0 \pm 0.1$ & $0.9 \pm 0.1$ & $0.9 \pm 0.1$ & 0.44 & 0.70 \\
\hline Fat (\% of energy) & $36.2 \pm 1.3$ & $33.5 \pm 0.8$ & $30.0 \pm 1.3$ & 0.12 & $<0.001$ \\
\hline Fat (g) & $90.7 \pm 5.6$ & $77.5 \pm 5.5$ & $65.6 \pm 4.6$ & 0.11 & $<0.001$ \\
\hline Saturated fat (g) & $33.3 \pm 1.7$ & $27.2 \pm 1.7$ & $19.0 \pm 1.4$ & $<0.01$ & $<0.001$ \\
\hline Monounsaturated fat (g) & $31.0 \pm 2.5$ & $27.1 \pm 2.2$ & $24.6 \pm 2.1$ & 0.21 & $<0.01$ \\
\hline Polyunsaturated fat (g) & $13.3 \pm 1.2$ & $12.7 \pm 1.1$ & $13.8 \pm 1.2$ & 0.71 & 0.99 \\
\hline Carbohydrate (\% of energy) & $40.2 \pm 1.6$ & $43.0 \pm 1.1$ & $49.7 \pm 1.6$ & 0.20 & $<0.001$ \\
\hline Dietary Fiber (g/d) & $23.9 \pm 1.3$ & $22.0 \pm 1.5$ & $23.4 \pm 2.6$ & 0.44 & 0.85 \\
\hline Protein (\% of energy) & $19.4 \pm 0.8$ & $20.1 \pm 0.8$ & $18.3 \pm 0.7$ & 0.50 & 0.20 \\
\hline Alcohol (g) & $12.1 \pm 2.1$ & $11.0 \pm 2.1$ & $5.8 \pm 1.7$ & 0.70 & 0.08 \\
\hline Calcium (mg) & $1226 \pm 44$ & $1300 \pm 53$ & $677 \pm 41$ & 0.60 & $<0.001$ \\
\hline
\end{tabular}

${ }^{a}$ All values are means \pm SEMs, $n=79$ because 6 (subjects had dietary records considered nonsufficient and were therefore removed from the model). Data were assessed by using 3-d weighted dietary record estimated using Dankost 3000 dietary assessment software (Dankost). Statistical differences were based on linear mixed models with values for average daily consumption at week 0 for all variables included as covariates. Pairwise comparisons were based on post hoc t- test with $p$-values adjusted for multiplicity. Abbreviations: $C H O$ carbohydrate control, RED reduced-fat cheese, REG regular-fat cheese

in particle number or HDL composition. In men, no significant differences were observed in HDL-C after the REG diet compared to the $\mathrm{CHO}$ diet. But, HDL-C in the larger HDL particles tended to be higher following the REG diet compared with the RED diet $(P=0.09)$. Whereas small, dense LDL particles have been associated with higher incidence of CVD and diabetes, the relation between HDL subfractions and CVD outcomes are more controversial. Large HDL particles have been suggested to be more cardio protective than small HDL particles [28-30], although not consistently [31, 32].

Despite the relatively large amount of intervention studies investigating the effects of cheese intake on the standard lipid profile compared with other dairy products [33-37], evidence regarding the effect of cheese on LDL particle size and lipoprotein subclasses remains scarce. In fact, the present study is to our knowledge the first randomized controlled feeding trial to evaluate the cardiometabolic effects of cheese intake beyond the standard lipid profile (TC, LDL-C and HDL-C). However, a few studies have investigated the impact of other dairy foods on LDL particle size [38-41]. In 35 healthy men and women $(>27 \mathrm{~kg} / \mathrm{m} 2)$ the impact on LDL particle size of low-fat dairy $(500 \mathrm{~mL}$ low-fat milk and $150 \mathrm{~g}$ low-fat yogurt) was compared with carbohydrate-rich foods (600 mL fruit juice and 3 fruit biscuits). The low-fat dairy did not alter LDL or HDL particle number compared with the carbohydrate diet [39]. In 14 normolipidemic men and women, the intake of $500 \mathrm{ml} / \mathrm{d}$ nonfat milk, but not whole-fat milk, was associated with larger LDL particles during a 2 wk. intervention [40]. In a 6-wk randomized, crossover study, in which 27 postmenstrual women consumed a diet with 3.2 servings/day of $2 \%$ fat milk or a milk and dairy free diet, no differences was observed on LDL particle size [38]. In healthy men, consumption of full-fat dairy (milk, butter, and cheese) and dairy products enriched with naturally derived trans fatty acids was not associated with changes in LDL particle size [41]. Lastly, consumption of high-fat dairy diet for $3 \mathrm{wk}$. did not alter LDL particle size, whereas consumption of low-fat dairy reduced LDL particle size compared with a control diet [25]. The results from these studies suggest that the effect of dairy on LDL particle size differs in regard to type of dairy product consumed, metabolic status of the population, and gender. Thus, more studies are needed to fully elucidate the impact of cheese and other dairy products on LDL particle size distribution.

The strength of the current study was its long duration, as it increased our ability to detect changes in lipoprotein profile over a longer time span. The inclusion of a 2 -wk run-in period with dietary restrictions (non-dairy restriction) is also strength as it allowed the subjects to physically adapt to the dietary changes and thereby help adjust for prior dietary habits. The fact that subjects maintained stable body weight throughout the intervention is an advantage, which (together with the statistical adjustment for individual changes in body weight) supports, that our results were independent of changes in body weight. Limitations of the present study include the fact that no power calculation was used; thus a potential risk of reporting false negatives. Compliance in this study was based on self-reporting, thus a potential risk of response bias is present. Also, the lack of biomarkers for assessment of dietary compliance is a limitation in this study. Lastly, because of the small sample size, especially in men, generalizability of the study 
results is limited and further research is therefore needed to determine the effect of regular-fat cheese on LDL particle size distribution.

\section{Conclusions}

In conclusion, regular-fat cheese did not alter overall LDL particle size distribution compared to reduced-fat cheese after a $12 \mathrm{wk}$. intervention in subjects with MetS. However, our results suggest that lipoprotein response to cheese intake is gender-specific. This warrants further investigation.

\section{Abbreviations}

Apo: Apolipoprotein; CHO: Carbohydrate control; CVD: Cardiovascular disease; HDL-C: High density lipoprotein cholesterol; IDL-C: Intermediate density lipoprotein cholesterol; IDL-P: Intermediate density lipoprotein particle number; LDL-C: Low density lipoprotein cholesterol; LDL-P: Low density lipoprotein particle number; RED: Reduced-fat cheese; REG: Regularfat cheese; VLDL-C: Very low density lipoprotein cholesterol; VLDL-P: Very low density lipoprotein particle number

\section{Acknowledgements}

We would like to thank Bruker Biospin GmbH Germany for providing access to B.I.-LISA. We also thank our kitchen staff Charlotte Kostecki, Karina Graff Rossen, Mona Jul Pedersen and Yvonne Fatum for preparing the intervention diets and our laboratory technicians Søren Andresen and Aminah Ishaq Palic for collecting and analyzing blood samples.

\section{Funding}

Arne Astrup has received research grants from Arla Foods AMBA, DK; The Danish Dairy Research Foundation, DK; Global Dairy Platform, USA and the Danish Agriculture and Food Foundation, DK. Tine Tholstrup has received research grants from Arla Foods AMBA, DK; The Danish Dairy Research Foundation, and the National Dairy Council, Rosemont, IL. Anne Raben has received research funding from the National Dairy Council, Rosemont, IL, USA and The Danish Agriculture \& Food Council, CPH, DK. Søren Balling Engelsen received funding from Innovation Fund Denmark and The Danish Dairy Research Foundation.

\section{Availability of data and materials}

The data are stored at an internal drive at NEXS.

\section{Sources of support}

The study was 50\% financed by the Danish Dairy Research Foundation, Danish Agriculture and Food Council (Denmark) and 50\% by the National Dairy Council (USA), the Dairy Farmers of Canada (Canada), Centre National Interprofessionel de l'Economie Laitière (France), Dairy Australia (Australia), and Nederlandse Zuivel Organisatie (the Netherlands).

\section{Authors' contributions \\ The authors' responsibility was as follows - AA and ARA: designed the study, FR: conducted the study, performed the statistical analyses, wrote the manuscript and had primary responsibility for the final content of the manuscript, ARA and TT: supplied valuable knowledge and scientific consultation throughout the study, PE and SE: performed the NMR lipoprotein analysis. The sponsors were invited to comment on the study design, but the researchers made the final decisions. The sponsors had no influence on the execution of the study, the analysis and interpretation of data, or on the final manuscript. All authors read and approved the final manuscript.}

\section{Ethics approval and consent to participate}

Protocol nr.: H-4-2013-099 and Trial reg. Number NCT0261471.

\section{Consent for publication}

All authors read and approved the final manuscript.

\section{Competing interests}

The authors declare that they have no competing interests.

\section{Publisher's Note}

Springer Nature remains neutral with regard to jurisdictional claims in published maps and institutional affiliations.

\section{Author details}

${ }^{1}$ Department of Nutrition, Exercise and Sports, Faculty of Science, University of Copenhagen, Rolighedsvej 26, 1958 Frederiksberg C, Denmark. ${ }^{2}$ Department of Food Science, Faculty of Science, University of Copenhagen, Rolighedsvej 26, 1958 Frederiksberg C, Denmark.

Received: 23 February 2018 Accepted: 5 September 2018

Published online: 21 September 2018

\section{References}

1. Scandinavian Simvastatin Survival Study Group, Randomised trial of cholesterol lowering in 4444 patients with coronary heart disease: the Scandinavian Simvastatin Survival Study (4S). Lancet (London, England). 1994:344:1383-9.

2. Genest JJ, McNamara JR, Salem DN, Schaefer EJ. Prevalence of risk factors in men with premature coronary artery disease. Am J Cardiol. 1991;67:1185-9.

3. Krauss RM, Burke DJ. Identification of multiple subclasses of plasma low density lipoproteins in normal humans. J Lipid Res. 1982;23:97-104.

4. Krauss RM. All low-density lipoprotein particles are not created equal. Arterioscler Thromb Vasc Biol. 2014;34:959-61.

5. Mora S, Caulfield MP, Wohlgemuth J, Chen Z, Superko HR, Rowland CM, Glynn RJ, Ridker PM, Krauss RM. Atherogenic lipoprotein subfractions determined by ion mobility and first cardiovascular events after random allocation to high-intensity statin or PlaceboCLINICAL PERSPECTIVE. Circulation. 2015;132:2220-9.

6. St-Pierre AC, Ruel IL, Cantin B, Dagenais GR, Bernard PM, Després JP, Lamarche B. Comparison of various electrophoretic characteristics of LDL particles and their relationship to the risk of ischemic heart disease. Circulation. 2001:104:2295-9.

7. Lamarche B, Lemieux I, Després JP. The small, dense LDL phenotype and the risk of coronary heart disease: epidemiology, patho-physiology and therapeutic aspects. Diabetes Metab. 1999;25:199-211.

8. National Cholesterol Education Program (NCEP) Expert Panel on Detection, Evaluation, and Treatment of High Blood Cholesterol in Adults (Adult Treatment Panel III). Third Report of the National Cholesterol Education Program (NCEP) Expert Panel on Detection. Evaluation, and treatment of high blood cholesterol in adults (adult treatment panel III) final report. Circulation. 2002;106:3143-421.

9. Dreon DM, Fernstrom HA, Campos H, Blanche P, Williams PT, Krauss RM. Change in dietary saturated fat intake is correlated with change in mass of large low-density-lipoprotein particles in men. Am J Clin Nutr. 1998;67:828-36

10. Siri PW, Krauss RM. Influence of dietary carbohydrate and fat on LDL and HDL particle distributions. Curr Atheroscler Rep. 2005;7:455-9.

11. Hjerpsted J, Tholstrup T. Cheese and cardiovascular disease risk: a review of the evidence and discussion of possible mechanisms. Crit Rev Food Sci Nutr. 2015:56:1389-403.

12. Chen G-C, Wang Y, Tong X, Szeto IMY, Smit G, Li Z-N, Qin L-Q. Cheese consumption and risk of cardiovascular disease: a meta-analysis of prospective studies. Eur J Nutr. 2016;56:2565-75.

13. Qin L-O, Xu J-Y, Han S-F, Zhang Z-L, Zhao Y-Y, Szeto IM. Dairy consumption and risk of cardiovascular disease: an updated meta-analysis of prospective cohort studies. Asia Pac J Clin Nutr. HEC Press. 2015;24:90-100.

14. Tong $X$, Chen G-C, Zhang Z, Wei Y-L, Xu J-Y, Qin L-Q. Cheese consumption and risk of all-cause mortality: a meta-analysis of prospective studies. Nutrients. 2017;9:63

15. Campos H, Dreon D, Krauss R. Associations of hepatic and lipoprotein lipase activities with changes in dietary composition and low density lipoprotein subclasses. J Lipid Res. 1995;36:462-72.

16. Campos H, Blijlevens E, McNamara JR, Ordovas JM, Posner BM, Wilson PW Castelli WP, Schaefer EJ. LDL particle size distribution. Results from the Framingham offspring study. Arterioscler Thromb a J Vasc Biol. 1992;12: $1410-9$. 
17. Dreon DM, Fernstrom HA, Miller B, Krauss RM. Low-density lipoprotein subclass patterns and lipoprotein response to a reduced-fat diet in men FASEB J. 1994:8:121-6.

18. Sjogren $P$, Rosell M, Skoglund-Andersson C, Zdravkovic S, Vessby B, de Faire U, Hamsten A, Hellenius M-L, Fisher RM. Milk-derived fatty acids are associated with a more favorable LDL particle size distribution in healthy men. J Nutr. 2004;134:1729-35

19. Raziani F, Tholstrup T, Kristensen MD, Svanegaard ML, Ritz C, Astrup A Raben A. High intake of regular-fat cheese compared with reduced-fat cheese does not affect LDL cholesterol or risk markers of the metabolic syndrome: a randomized controlled trial. Am J Clin Nutr. 2016;104: 973-81.

20. Dona AC, Jiménez B, Schäfer H, Humpfer E, Spraul M, Lewis MR, Pearce JTM,

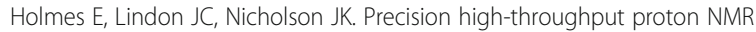
spectroscopy of human urine, serum, and plasma for large-scale metabolic phenotyping. Anal Chem. 2014;86:9887-94.

21. Petersen M, Dyrby M, Toubro S, Engelsen SB, Nørgaard L, Pedersen HT, Dyerberg J. Quantification of lipoprotein subclasses by proton nuclear magnetic resonance-based partial least-squares regression models. Clin Chem. 2005:51(8):1457-61.

22. Aru V, Lam C, Khakimov B, Hoefsloot HCJ, Zwanenburg G, Lind MV, Schäfer H, van Duynhoven J, Jacobs DM, Smilde AK, Engelsen SB. Quantification of lipoprotein profiles by nuclear magnetic resonance spectroscopy and multivariate data analysis. TrAC, Trends Anal Chem. 2017;94:210-9.

23. R Core Team. R: A language and environment for statistical computing. Vienna: R Foundation for Statistical Computing; 2015

24. Hothorn T, Bretz F, Westfall P. Simultaneous inference in general parametric models. Biom J. 2008;50:346-63.

25. Chiu S, Bergeron N, Williams PT, Bray GA, Sutherland B, Krauss RM. Comparison of the DASH (dietary approaches to stop hypertension) diet and a higher-fat DASH diet on blood pressure and lipids and lipoproteins: a randomized controlled trial. Am J Clin Nutr. 2016;103:341-7.

26. Campos H, McNamara JR, Wilson PWF, Ordovas JM, Schaefer EJ. Differences in low density lipoprotein subfractions and apolipoproteins in premenopausal and postmenopausal women. J Clin Endocrinol Metab. 1988;67:30-5.

27. Mensink RP, Zock PL, Kester ADM, Katan MB. Effects of dietary fatty acids and carbohydrates on the ratio of serum total to HDL cholesterol and on serum lipids and apolipoproteins: a meta-analysis of 60 controlled trials. Am J Clin Nutr. 2003;77:1146-55.

28. El Harchaoui K, Arsenault BJ, Franssen R, Després J-P, Hovingh GK, Stroes ESG, Otvos JD, Wareham NJ, Kastelein JJP, Khaw K-T, et al. High-density lipoprotein particle size and concentration and coronary risk. Ann Intern Med. 2009;150:84-93.

29. Goff DC, D'Agostino RB, Haffner SM, Otvos JD. Insulin resistance and adiposity influence lipoprotein size and subclass concentrations. Results from the insulin resistance atherosclerosis study. Metabolism. 2005;54:264-70.

30. Festa A, Williams K, Hanley AJG, Otvos JD, Goff DC, Wagenknecht LE, Haffner SM. Nuclear magnetic resonance lipoprotein abnormalities in Prediabetic subjects in the insulin resistance atherosclerosis study. Circulation. 2005;111:3465-72.

31. Otvos JD, Collins D, Freedman DS, Shalaurova I, Schaefer EJ, McNamara JR, Bloomfield HE, Robins SJ. Low-density lipoprotein and high-density lipoprotein particle subclasses predict coronary events and are favorably changed by gemfibrozil therapy in the veterans affairs high-density lipoprotein intervention trial. Circulation. 2006:113:1556-63.

32. Mora S, Szklo M, Otvos JD, Greenland P, Psaty BM, Goff DC, O'Leary DH, Saad MF, Tsai MY, Sharrett AR. LDL particle subclasses, LDL particle size, and carotid atherosclerosis in the multi-ethnic study of atherosclerosis (MESA). Atherosclerosis. 2007;192:211-7.

33. Nestel PJ, Chronopulos A, Cehun M. Dairy fat in cheese raises LDL cholesterol less than that in butter in mildly hypercholesterolaemic subjects. Eur J Clin Nutr. 2005;59:1059-63.

34. Biong AS, Müller $H$, Seljeflot I, Veierød MB, Pedersen II. A comparison of the effects of cheese and butter on serum lipids, haemostatic variables and homocysteine. Br J Nutr. 2004;92:791-7.

35. Soerensen KV, Thorning TK, Astrup A, Kristensen M, Lorenzen JK. Effect of dairy calcium from cheese and milk on fecal fat excretion, blood lipids, and appetite in young men. Am J Clin Nutr. 2014;99:984-91.

36. Hjerpsted J, Leedo E, Tholstrup T. Cheese intake in large amounts lowers LDL-cholesterol concentrations compared with butter intake of equal fat content. Am J Clin Nutr. 2011;94:1479-84.
37. Tholstrup T, Høy C-E, Andersen LN, Christensen RDK, Sandström B. Does fat in milk, butter and cheese affect blood lipids and cholesterol differently? J Am Coll Nutr. 2004;23:169-76.

38. Drouin-Chartier J-P, Gagnon J, Labonté M-Ė, Desroches S, Charest A, Grenier G, Dodin S, Lemieux S, Couture P, Lamarche B. Impact of milk consumption on cardiometabolic risk in postmenopausal women with abdominal obesity. Nutr J. 2015;14:12

39. van Meijl LE, Mensink RP. Low-fat dairy consumption reduces systolic blood pressure, but does not improve other metabolic risk parameters in overweight and obese subjects. Nutr Metab Cardiovasc Dis. 2011;21:355-61.

40. Hidaka H, Takiwaki M, Yamashita M, Kawasaki K, Sugano M, Honda T. Consumption of nonfat Milk results in a less Atherogenic lipoprotein profile: a pilot study. Ann Nutr Metab. 2012;61:111-6.

41. Tricon S, Burdge GC, Jones EL, Russell JJ, El-Khazen S, Moretti E, Hall WL, Gerry AB, Leake DS, Grimble RF, et al. Effects of dairy products naturally enriched with cis-9,trans-11 conjugated linoleic acid on the blood lipid profile in healthy middle-aged men. Am J Clin Nutr. 2006;83:744-53.
Ready to submit your research? Choose BMC and benefit from:

- fast, convenient online submission

- thorough peer review by experienced researchers in your field

- rapid publication on acceptance

- support for research data, including large and complex data types

- gold Open Access which fosters wider collaboration and increased citations

- maximum visibility for your research: over $100 \mathrm{M}$ website views per year

At BMC, research is always in progress.

Learn more biomedcentral.com/submissions 